\title{
Transaortic repair of blunt traumatic cardiac wall and papillary muscle rupture
}

\author{
Martin Misfeld, MD, a Philipp Ehlermann, MD, ${ }^{\mathrm{b}}$ and Hans-Hinrich Sievers, MD, FECTS, ${ }^{\text {a Lübeck, Germany }}$
}

A cute cardiac rupture after blunt chest trauma is common $^{1}$ and associated with a high mortality. ${ }^{2,3}$ Delayed cardiac rupture after blunt chest injuries may have a better outcome. Appropriate strategies and surgical repair are necessary.

We report a case of delayed cardiac wall and partial papillary muscle rupture after blunt chest trauma and an uncommon technique of transaortic repair.

\section{Clinical Summary}

Our patient was an 18-year-old man with blunt chest trauma during a car accident. Transesophageal echocardiography (TEE) demonstrated transection of the aorta about $2 \mathrm{~cm}$ distal to the left subclavian artery. Dimensions of the heart chambers were normal. There was a minimal pericardial effusion, and the heart valves were competent. Laboratory data revealed a creatine kinase level of $590 \mathrm{U} / \mathrm{L}$ (normal range, 10-70 U/L), with a total creatine kinase muscle brain fraction of $63 \mathrm{U} / \mathrm{L}$ (normal range, 0-10 U/L). The result of troponin $\mathrm{T}$ testing was positive without signs of ischemia on the electrocardiogram.

Over the next hours, cardiopulmonary insufficiency developed, and the patient was intubated and his lungs were ventilated. Transection of the aorta was treated conservatively. Hemodynamic status deteriorated further in the following days. Daily TEEs showed severe mitral regurgitation with partial rupture of the mitral anterior papillary muscle and hemodynamically relevant pericardial effusion for the first time on day 3 after the accident. Left heart catheterization confirmed mitral insufficiency of grade III to IV. Mean pulmonary artery pressure was $57 \mathrm{~mm} \mathrm{Hg}$. The coronary arteries were normal. Right heart catheterization demonstrated large $\mathrm{V}$ waves.

Inspection of the left ventricle revealed a nonpenetrating rupture of the left ventricle in the area between the circumflex artery

From the Clinic of Cardiac Surgery a and Department of Medicine II, ${ }^{\mathrm{b}}$ University Clinic of Lübeck, Lübeck, Germany.

Received for publication Feb 5, 2001; accepted for publication Feb 16, 2001.

Address for reprints: Hans-Hinrich Sievers, MD, Clinic of Cardiac Surgery, University Clinic of Lübeck, Ratzeburger Allee 160, 23538 Lübeck, Germany (E-mail: sievers@medinf.mu-luebeck.de).

J Thorac Cardiovasc Surg 2001;122:834-5

Copyright () 2001 by The American Association for Thoracic Surgery

$0022-5223 / 2001 \$ 35.00+0 \quad \mathbf{1 2 / 5 4 / 1 1 5 1 5 4}$

doi: $10.1067 / \mathrm{mtc} .2001 .115154$ and the left anterior descending artery covered by dense fibrin material. After removal of this material, a complete 2-cm rupture was visible. Visualization of the left ventricular chamber through the left atrium was not sufficient, and therefore a transaortic approach was chosen. The anterior papillary muscle was partially torn in the area of the ruptured left ventricular wall. The epicardial edges of the tear were approximated by a continuous 4-0 Prolene suture (Ethicon, Inc, Somerville, NJ). In addition, a supportive pericardial patch was sutured over the rupture on both sides of the tear with 5-0 Prolene sutures.

The mitral valve was reconstructed through the aortic valve by reinserting the anterior papillary muscle into the lateral ventricular wall with a transmyocardial U-shaped Teflon-buttressed 3-0 Prolene suture (Figure 1). The sutures passed the myocardium on both sides of the rupture, thereby supporting the closure of the defect (Figure 2). Postoperative transthoracic echocardiography showed a remaining mild-to-moderate mitral regurgitation. Left atrial pressure was 25 over $17 \mathrm{~mm} \mathrm{Hg}$.

Postoperative TEE studies demonstrated no change in the grade of mitral regurgitation. After repair of the traumatic aortic rupture, the patient is in excellent condition 2 months after the accident.

\section{Discussion}

Although acute cardiac rupture is common after blunt chest injuries, ${ }^{1}$ it is rarely seen in the operating theater because of its high mortality. Only a handful of patients survive. In contrast to most reports of acute cardiac rupture, ${ }^{2,3}$ only a few reports describe delayed rupture hours after the accident. ${ }^{4}$ Additionally, acute mitral valve injury leading to mitral regurgitation has been reported to be an uncommon complication after blunt chest trauma. ${ }^{5}$ To our knowledge, successful repair through a transaortic approach has never been reported before.

Traumatic mitral valve regurgitation is usually caused by disruption of the mitral leaflets or the different parts of the subvalvular apparatus after myocardial contusion. ${ }^{5}$ In our case, the subvalvular mitral apparatus was ruptured at the level of the left ventricular wall, where the papillary muscle was partially torn out of the wall, leading to mitral valve prolapse and nonpenetrating cardiac rupture. An explanation for the delayed onset of the mitral regurgitation could be myocardial necrosis in the area of the torn papillary muscle. Although angiography showed normal coronary arteries, microinfarctions caused by contusion could not been excluded. Another pathomechanism could be an initially slight tear at the base of the papillary muscle, which increases in size by time, stress, and tension during recovery in the intensive care unit, with hypertensive periods probably caused by reflex mechanisms after transection of the aorta. 

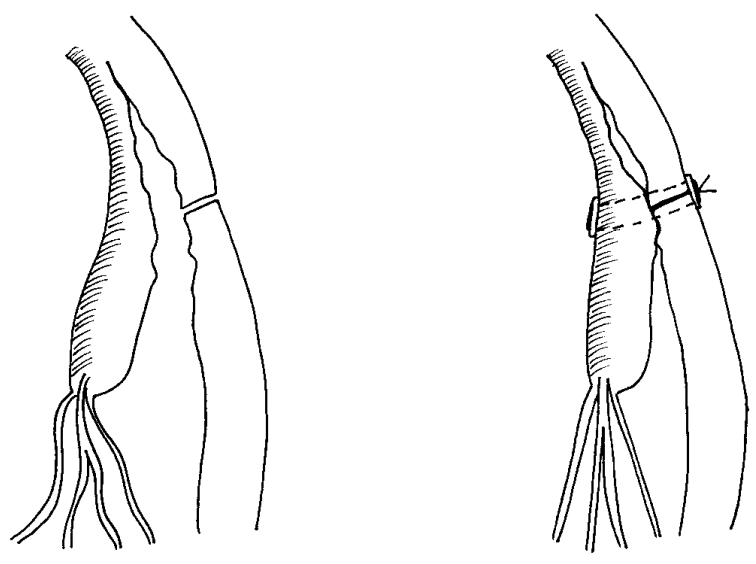

Figure 1. Operative view of the anterior mitral papillary muscle and left ventricular wall before and after reattachment of the papillary muscle with simultaneous closure of the ventricular rupture.

The transaortic approach provided excellent access to the subvalvular mitral apparatus and should be considered as an alternative to the routine approach through the left or right atrium. The remaining mild-to-moderate mitral insufficiency was accepted in this young patient to avoid valve replacement with a mechanical valve.

In conclusion, the combination of delayed cardiac wall and papillary muscle rupture after blunt chest trauma is uncommon but should be kept in mind in deteriorating hemodynamic conditions. Serial TEE studies were useful to reveal the correct diagnosis. Surgical techniques like the one described could lead to an adequate treatment of these high-risk patients.

\section{References}

1. Parmley LF, Manion WC, Mattingly TVV. Nonpenetrating traumatic injury of the heart. Circulation. 1958;18:371-96.

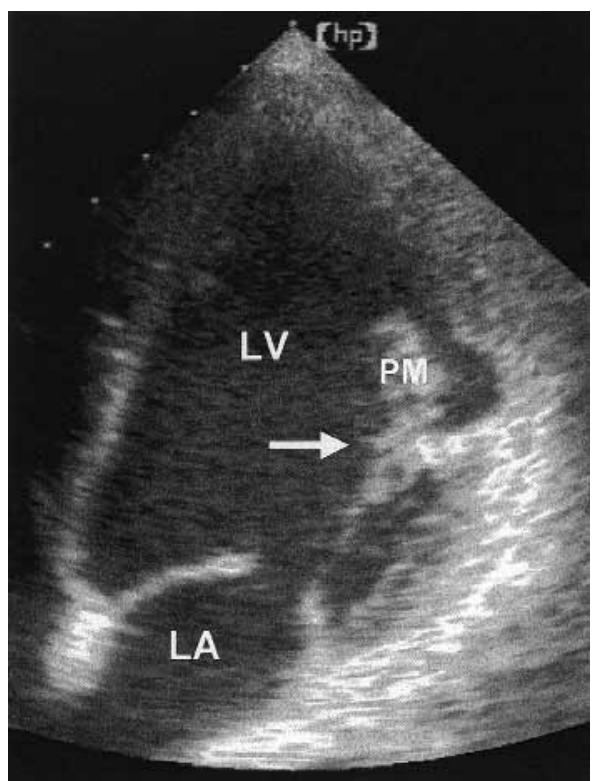

Figure 2. Transthoracic echocardiography showing the left ventricle $(L V)$ and left atrium $(L A)$ in diastole. The arrow illustrates the reattached anterior papillary muscle (PM) into the left ventricular wall.

2. Brathwaite CE, Rodriguez A, Tumey SZ, Dunham CM, Cowley R. Blunt traumatic cardiac rupture. A 5-year experience. Ann Surg. 1990;212:701-4.

3. Hendel PN, Grant AF. Blunt traumatic rupture of the heart: successful repair of simultaneous rupture of the right atrium and left ventricle. $J$ Thorac Cardiovasc Surg. 1981;81:574-6.

4. Weiner Y, Berkenstadt H, Segal E. Survival after left ventricular rupture following blunt chest injury. Am J Emerg Med. 1996;14:186-8.

5. McDonald ML, Orszulak TA, Bannon MP, Zietlow SP. Mitral valve injury after blunt chest trauma. Ann Thorac Surg. 1996;61:1024-9. 